\title{
Rectal mucosal ornithine decarboxylase activity in familial adenomatous polyposis after ileorectal
} anastomosis

\author{
S E Patchett, E M Alstead, L Trzeciak, T Wocial, R K S Phillips, M J G Farthing
}

\begin{abstract}
Resection of the colon in patients with familial adenomatous polyposis frequently results in the regression of polyps in the remaining rectum, suggesting a reduction of cellular proliferation. These patients remain at risk of developing rectal cancer but whether this risk increases with time is uncertain. Since ornithine decarboxylase activity is associated with cellular proliferation, mucosal ornithine decarboxylase was measured in rectal biopsy specimens from patients with familial adenomatous polyposis after ileorectal anastomosis $(n=36)$ and from normal controls $(n=30)$. The relationship between ornithine decarboxylase activity, age, and time from surgery was also examined. Median ornithine decarboxylase activity in familial adenomatous polyposis patients after ileorectal anastomosis (186, interquartile range (IQR) 107-534 $\mathrm{pmol} / \mathrm{mg}$ protein/h) was not different from that in control subjects $(227$, IQR $123-374$, $p=0 \cdot 6$ ). When patients were divided into three equal groups according to age, however, younger patients ( $<25$ years) had significantly higher activity than both older age groups $(p<0.02)$. Similarly, when patients were stratified according to the time elapsed since surgery, those who had had surgery less than six years previously had a significantly higher ornithine decarboxylase activity than those in whom a longer time interval had elapsed since surgery $(p=0 \cdot 02)$. These results indicate that after colon resection, ornithine decarboxylase activity in patients with familial adenomatous polyposis is similar to that in normal controls but seems to fall over time. This may explain the regression of rectal polyps after colonic resection in this disorder.

(Gut 1994; 35: 1624-1626)
\end{abstract}

Gastroenterology,

St Bartholomew's and

St Mark's Hospitals,

London

$S$ E Patchett

E M Alstead

L Trzeciak

T Wocial

R K S Phillips

M J G Farthing

Correspondence to: Dr S E Patchett, Department of Gastroenterology St Bartholomew's Hospital, West Smithield

Accepted for publication 11 March 1994

Familial adenomatous polyposis (FAP) is dominantly inherited disorder characterised by the development of multiple adenomatous polyps throughout the gastrointestinal tract, followed inevitably by colon cancer in untreated patients. ${ }^{2}$ Most patients will develop a colonic carcinoma by the age of 40 years unless a prophylactic colectomy is performed, and thus a subtotal colectomy is now routinely performed in young adulthood in patients with this disorder. ${ }^{3}$ Restorative proctocolectomy has been advocated in preference to subtotal colectomy with ileorectal anastomosis in this group to abolish the risk of subsequent cancer development in the remaining rectum. ${ }^{4}$ Many centres, however, still favour subtotal colectomy with ileorectal anastomosis as the procedure of choice as it is a comparatively safe and simple procedure with an excellent functional result. ${ }^{56}$ Additionally, surveillance of the remaining rectum and removal of recurrent polyps is a simple procedure. The potential for development of malignancy in the upper gastrointestinal tract is now felt by some to outweigh the risks of cancer development in the rectum. ${ }^{6}$ It is of particular interest, however, that after subtotal colectomy, there may be spontaneous resolution of polyps in the rectum. ${ }^{78}$ The factors involved in producing this unexpected beneficial effect of subtotal colectomy are unknown, although changes in the local environment such as an alteration in the bacterial population or faecal bile acid concentrations may have a role. ${ }^{9} 10$

As both cancer and polyp formation are associated with increased mucosal proliferation, ${ }^{1112}$ it is likely that polyp regression is related to a reduced proliferative rate. Ornithine decarboxylase is the rate limiting enzyme in the polyamine biosynthetic pathway and has been shown to be closely related to mucosal proliferation and malignant transformation. ${ }^{1314}$ In order to compare mucosal proliferation in normal subjects and patients with FAP, we have measured rectal ornithine decarboxylase activity in consecutive patients with FAP who have undergone prophylactic total colectomy with ileorectal anastomosis. In order to examine the effect of subtotal colectomy, we have also investigated the relationship of ornithine decarboxylase activity to patient age and to the length of time from colectomy.

Methods

We studied 36 patients with FAP who were attending the polyposis clinic at St Mark's hospital and who had undergone subtotal
TABLE I Characteristics of familial adenomatous polyposi (FAP) patients and healthy controls

\begin{tabular}{|c|c|c|c|}
\hline & $F A P$ & $\begin{array}{l}\text { Healthy } \\
\text { controls }\end{array}$ & $\stackrel{p}{\text { Value }}$ \\
\hline $\begin{array}{l}\text { No } \\
\text { Age (median (range) }(y)\end{array}$ & 36 & 30 & \\
\hline $\begin{array}{l}\text { Age (median (range)) (y) } \\
\text { Sex (male/female) }\end{array}$ & $\begin{array}{l}36(19-11) \\
20 / 16\end{array}$ & $\begin{array}{l}31(19-81) \\
13 / 17\end{array}$ & $\begin{array}{l}0.4 \\
0.5\end{array}$ \\
\hline Time from surgery (y) & $13 \cdot 5(3-39)$ & & \\
\hline
\end{tabular}




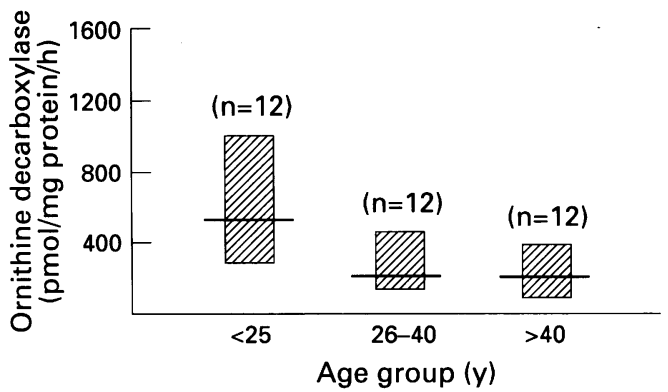

Figure 1: Comparison of ornithine decarboxylase activity in three groups stratified for age. Data are expressed as medians with interquartile ranges $(p<0 \cdot 02, A N O V A)$.

colectomy with ileorectal anastomosis for cancer prophylaxis. The clinical and demographic details of each patient are summarised in Table I. All subjects underwent rigid sigmoidoscopy as part of a surveillance protocol. Each patient was prepared with a single phosphate enema and two rectal biopsy specimens were obtained from normal looking flat mucosa from the posterior wall at less than $10 \mathrm{~cm}$ from the anal verge. Specimens were immediately frozen in liquid nitrogen and stored at $-70^{\circ} \mathrm{C}$ until the ornithine decarboxylase assay was performed. For comparison, normal rectal mucosal biopsy specimens were obtained at colonoscopy from 30 subjects with no endoscopic or histological abnormality and with a final diagnosis of the irritable bowel syndrome.

Mucosal ornithine decarboxylase was assayed using a modification of the method described by Beaven et al. ${ }^{15}$ Rectal mucosal specimens were homogenised in $300 \mu$ l of

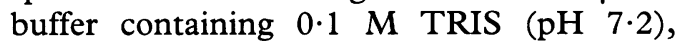
$5 \mathrm{mM}$ dithiothreitol, and $0.25 \mathrm{mM}$ pyridoxal phosphate. The reaction mixture consisted of $15 \mu \mathrm{l}$ of homogenate, $0.25 \mathrm{mM}$ pyridoxal phosphate, $5 \mathrm{mM}$ DTT with $0.15 \mu \mathrm{Ci}$ of $\mathrm{L}-\left[{ }^{14} \mathrm{C}\right]$-ornithine hydrochloride (Amersham International) in a total volume of $30 \mu \mathrm{l}$. The reaction tube was sealed with a rubber cap in which was embedded a $0.5 \times 0.5 \mathrm{~cm}$ square of Whatman no 1 filter paper soaked with $50 \mu$ l methylbenzethonium hydroxide. Tubes were incubated at $37^{\circ} \mathrm{C}$ for 60 minutes and the reaction was then stopped by injecting $100 \mu 120 \%$ TCA. After a further 30 minutes, incubation, the filter paper was removed and placed in $5 \mathrm{ml}$ of scintillation liquid and counted in an LKB Wallac RACKbeta 1210 scintillation counter. Results were expressed as pmol of $\left[{ }^{14} \mathrm{C}\right] \mathrm{O}_{2}$ released per hour per $\mathrm{mg}$ of tissue protein. The protein content of the homogenate was estimated using the bicinchoninic acid microtitre protein assay (Pierce). All assays were

TABLE II Relationship between age and ornithine decarboxylase (ODC) activity in familial adenomatous polyposis (FAP) patients (median with interquartile ranges)

\begin{tabular}{lll}
\hline & \multicolumn{3}{l}{ ODC activity (pmol/mg protein/h) } \\
\cline { 2 - 3 } Age $(y)$ & FAP patients $(n=36)$ & Controls $(n=30)$ \\
\hline$<25$ & $523(273-1002)$ & $274(131-350)$ \\
$26-40$ & $175(130-453)$ & $260(110-374)$ \\
$>40$ & $139(73-381)$ & $226(121-500)$ \\
\hline
\end{tabular}

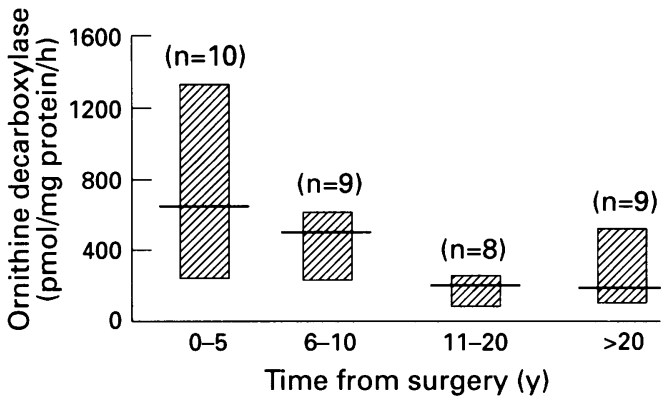

Figure 2: Comparison of ornithine decarboxylase activity in groups stratified according to time from surgery. Data are expressed as medians with interquartile ranges $(p<0.02$, ANOVA).

performed in duplicate and included negative controls.

Data were expressed as median and interquartile ranges. The $\chi^{2}$ statistic and Mann-Whitney $U$ tests were used to analyse discrete and continuous variables respectively where appropriate. Analysis of variance (ANOVA) was used to compare ornithine decarboxylase activities between groups stratified for age and time from surgery. A probability of $\mathrm{p}<0.05$ was considered significant in all analyses.

\section{Results}

Patients with FAP did not differ significantly from healthy controls in respect of age or sex (Table I). Median mucosal ornithine decarboxylase activity did not differ significantly between normal subjects and subjects with FAP (227, interquartile range (IQR) $123-374 v 186$, IQR $107-534 \mathrm{pmol} / \mathrm{mg}$ protein $/ \mathrm{h} ; \mathrm{p}=0 \cdot 6)$. When subjects with FAP were stratified into approximately equal groups for age, a raised ornithine decarboxylase activity was noted in patients under 25 years (523, IQR 273-1002) which was significantly greater than patients aged between 26-40 years (175, IQR 130-453) or those more than 40 years $(139$, IQR $73-381)(p=0.02)$ (Fig 1$)$. No variation with age was noted in normal subjects in this study (Table II). A similar pattern was observed when subjects were stratified into approximately equal groups according to the time elapsed since the ileorectal anastomosis (Fig 2). Subjects who had undergone surgery in the five years before the study had significantly higher ornithine decarboxylase activities than those in whom six years or more had elapsed since surgery. Median ornithine decarboxylase activity in subjects who had had surgery within the previous five years was 523 (IQR 186-1096), which was also significantly higher than healthy subjects $(p<0.01)$. Thus mucosal ornithine decarboxylase activity falls with time after subtotal colectomy and ileorectal anastomosis.

\section{Discussion}

Several investigators have documented a hyperproliferative state in patients with FAP. ${ }^{16} 17$ Rectal mucosal ornithine decarboxylase activity 
has been shown to be higher in symptomatic patients with polyps than in asymptomatic family members, and also in abnormal polypoid mucosa compared with normal mucosa of affected individuals. ${ }^{18}$ Most patients with FAP, however, undergo a prophylactic colectomy at a young age in order to prevent cancer development. Faecal bile acid composition and faecal bacterial flora are known to be altered by colectomy in these patients and this may influence mucosal proliferation in the rectum. ${ }^{9} 19$ The clinical observation of polyp regression after colectomy suggests that mucosal proliferation in the rectum may be reduced by this procedure. A reduction in mucosal proliferation has been confirmed shortly after colectomy in these patients and this has been related to changes in faecal bile acid concentrations. ${ }^{19}$ A recent study from St Mark's hospital has also suggested that rectal mucosal proliferation in patients with ileorectal anastomosis is significantly lower than in patients with FAP and an intact colon. ${ }^{20}$

In contrast to some previous studies, ${ }^{18}$ we have not found a significant difference in ornithine decarboxylase activity between normal subjects and patients with FAP who have undergone ileorectal anastomosis. We have, however, shown that the youngest patients with FAP, and those who have undergone surgery within five years of the study, had very significantly higher ornithine decarboxylase activities. These factors are obviously closely related as almost all patients are young when they undergo a colectomy. Although we did not examine mucosal ornithine decarboxylase activity in FAP patients preoperatively, the reduction over time after the procedure suggests that removal of the colon in these patients has an inhibitory effect on polyamine production in the rectum. Indeed it is probable the preoperative ornithine decarboxylase activity is considerably greater than that in the early postoperative years and this would be consistent with polyp resolution despite a seemingly high ornithine decarboxylase activity. The mechanism by which a reduction in polyamine biosynthesis occurs is unclear but may be related to the altered luminal environment to which the rectal mucosa is exposed. As reduced mucosal proliferation is usually accompanied by reduced polyamine production and this may partly explain why polyps regress after colectomy in FAP. None the less, a significant risk of rectal cancer remains after ileorectal anastomosis in patients with FAP and they require regular, long term follow up. ${ }^{4}$

Although ornithine decarboxylase is felt to be essential for malignant transformation, ${ }^{14}$ many other factors are involved in cancer development in human gut mucosa. Indeed, studies in animals have shown that a reduction in cellular proliferation by agents such as calcium are not always associated with a reduction in experimentally induced colon cancer. ${ }^{21}$ Our findings do, however, indicate that removal of the colon with the inevitable alteration in the luminal environment in the rectum in patients with FAP is associated with a reduction in ornithine decarboxylase activity in the remaining rectum. This is consistent with the observed clinical phenomenon of polyp regression after surgery.

SEP is supported by the Joint Research Board of St Bartholomew's Hospital.

1 Bussey HJR, Veale AMO, Morson BC. Genetics of gastrointestinal polyposis. Gastroenterology 1978; 74: 1325-30.

2 Northover JM, Murday V. Familial colorectal cancer and familial adenomatous polyposis. Ballières Clin Gastroenterol 1989; 3: 593-613.

3 Skinner MA, Tyler D, Branum GD, Cucchiaro G, Branum MA, Meyers WC. Subtotal colectomy for familial polyposis. A clinical series and review of the literature. Arch Surg 1990; 125: 621-4.

4 Slors JF, den Hartog Jager FC, Trum JW, Taat CW, Brummelkamp WH. Long-term follow-up after colectomy and ileorectal anastomosis in familial adenomatous polyposis coli. Is there still a place for the procedure? posis coli. Is there still a place for
Hepatogastroenterology 1989; 36: 109-12.

5 Jepatogastroenterology 1989; 36: 109-12. polyposis. World $\mathcal{F}$ Surg 1991; 15: 47-9.

6 Jagelman DG. Ileorectal anastomosis-familial adenomatous polyposis. Hepatogastroenterology 1991; 38: 535-7.

7 Hubbard TB. Familial polyposis of the colon: the role of the retained rectum after colectomy in children. Am $\mathcal{f}$ Surg 1957; 23: 577-86.

8 Feinberg SM, Jagelman DG, Sarre RG, McGannon E, Fazio VW, Lavery IC, et al. Spontaneous resolution of rectal polyps in patients with familial polyposis following abdominal colectomy and ileorectal anastomosis. Dis Colon Rectum 1988; 31: 169-75.

9 Natori H, Utsunomiya J, Yamamura T, Benno Y, Uchida $\mathrm{K}$. Fecal and stomal bile acid composition after ileostomy or ileoanal anastomosis in patients with chronic ulcerative colitis and adenomatosis coli. Gastroenterology 1992; 102: 1278-88.

10 Spigelman AD, Owen RW, Hill MJ, Phillips RK. Biliary bile acid profiles in familial adenomatous polyposis. $B r \mathcal{F}$ Surg 1991; 78: 321-5.

1 Terpstra OT, van Blankenstein M, Dees J, Eilers GAM Abnormal pattern of cell proliferation in the entire colonic mucosa of patients with colon adenoma or cancer. Gastroenterology 1987; 92: 704-8.

12 Romagnoli P, Fillipponi F, Bandettini L, Brugnola D. Increase of mitotic activity in the colonic mucosa of patients with colorectal cancer. Dis Colon Rectum 1984; 27 patients

13 Luk GD, Marton LJ, Baylin SB. Ornithine decarboxylase is important in intestinal mucosal maturation and recovery important in intestinal mucosal maturation and

14 Auvinen M, Paasinen A, Andersson LC, Hölttä E Ornithine decarboxylase activity is critical for cell transformation. Nature 1922; 360: 355-8.

15 Beaven MA, Wilcox G, Terpstra GK. A microprocedure for the measurement of ${ }^{14} \mathrm{CO}_{2}$ release from $\left[{ }^{14} \mathrm{C}\right]$ carboxyllabelled amino acids. Anal Biochem 1987; 84: 638-41.

16 Deschner EE, Lipkin $M$. Proliferative patterns in colonic mucosa in familial polyposis. Cancer 1975; 35: 1245-51.

17 Iwama T, Utzunomiya J, Sasaki J. Epithelial cell kinetics in the crypts of familial polyposis of the colon. Fapanese fournal of Surgery 1977; 7: 230-4.

18 Luk GD, Baylin SB. Ornithine decarboxylase as a biological marker in familial colonic polyposis. $N$ Engl 7 Med 1984 311: $80-3$.

19 Cats $A$ Kleibeuker JH, Kuipers $F$ Hardonk MJ Verschueren RC, Boersma W, et al. Changes in recta epithelial cell proliferation and intestinal bile acids after subtotal colectomy in familial adenomatous polyposis. Cancer Res 1992; 52: 3552-7.

20 Farmer KCR, Phillips RKS. Reduced mucosal proliferation after ileorectal anastomosis in familial adenomatous polyposis may explain rectal polyp regression. Gut 1991; 32 A1203.

21 Barsoum GH, Thompson H, Neoptolemos JP, Keighley MRB. Dietary calcium does not reduce experimental colorectal carcinogenesis after small bowel resection despite reducing cellular proliferation. Gut 1992; 33: 1515-20. 